\title{
Support to Order Management and Collaborative Production of Customised Garments for Specific Target Groups
}

\author{
Eva Coscia ${ }^{1}$, Michele Sesana ${ }^{1}$, and Rosanna Fornasiero ${ }^{2}$ \\ ${ }^{1}$ TXT e-solutions s.p.a Via Frigia 2720126 Milano, Italy \\ \{Eva.Coscia, Michele. Sesana\} @txtgroup.com \\ ${ }^{2}$ ITIA CNR Via Bassini 1520133 Milano, Italy \\ rosanna.fornasiero@itia.cnr.it
}

\begin{abstract}
This paper describes a solution for the creation and management of orders and other business documents, necessary for the production and delivery of customised garments. These documents are managed along a supply network that can be quickly set up with the support of a tool for the identification of best partners for the production of the ordered items. The management of the documents leverages on three elements: the adoption of a standard for the interoperability of the business information among different services used in the network; the usage of a tool for quickly and automatically check the documents' contents applying business rules on top of them; a middleware layer that provides a fast way of exchanging the checked documents. The set-up of the supply chain is supported by the Partner Search module which is in charge of managing and improving the manufacturer's knowledge about its potential partners. The solution is validated within an industrial pilot focused on the production of customised knitted items for obese people.
\end{abstract}

Keywords: supply chain management; business document exchange, customized order, partner search.

\section{$1 \quad$ Introduction}

This paper presents a new approach, developed in the context of the CoReNet ${ }^{1}$ project, for the creation of orders and for the production of customized items for specific groups of consumers that have functional and healthy requirements, such as, for example, obese people. The production of a single lot or of small series in a short time and with acceptable prices is a complex task for fashion companies (especially SMEs) that require a support during all the phases of this process, from market analysis and collection design, to item production, delivery and validation by the final consumer.

\footnotetext{
${ }^{1}$ FP7 NMP 260169 CoreNet (Customer-ORiented and Eco-friendly NETworks for healthy fashionable goods) project website: http: //www. corenet-project.eu 
The solution presented in this paper supports companies in three business processes: product configuration during the sales process, management of customized orders and other business documents exchanged along the supply chain during production process and the quick set up a of the supply chain for the order fulfilment. These aspects emerged as important steps especially for companies willing to change from standard orders to customized orders where many different parameters have to be verified before production starts.

The usage of standards ensures interoperability of the business documents exchanged between the tools used in the various phases and allows applying checking rules on the information shared by the involved actors along the supply chain. Furthermore, the research of the best partners supporting the manufacturer in the production of the customised items is empowered by a tool for the creation and maintenance of profiles of potential partners providing the partners themselves with the possibility to update their profile with information on their production availability.

\section{The General Reference Model and a Specific Instantiation: the Knitting Production Business Case}

Companies in the Textile, Clothing and Footwear Industry (TCFI), facing the challenge of producing single items or small series of customized items, need support in order to re-design their processes and take advantage of implementing new ICT tools to support them. The CoReNet Reference Model [1] is based on the formalization of the most important business processes requiring collaboration amongst different partners (from product conception and design, to production and delivery), and provides also guidelines along three important dimensions namely organizational changes, ICT and implementation of innovative tools supporting, and knowledge management.

Within this work, the new approach to network management has been validated within an industrial Pilot, called the Knitted Garments Pilot (KGP), where an important fashion company plays the role of the manufacturer. This company, specialized in the production of high-quality fashionable garments, is interested in extending its business to the design and production of garments for obese people, allowing them to order personalized (in sizes and in aesthetical aspects) items. According to the CoRM formalization and the business requirements collected with the company, the new approach proposed for the KGP aims to manage the networks both upstream towards the suppliers and downstream towards the customers and it is based on:

- Organizational revision of the business processes: the sales process is reengineered to support a new relationship with the customer to ease the formalization of her/his specific needs and to manage the order collection and the product delivery. The relationship with the third parties involved in different working phases need to be based on a more collaborative approach where the third parties can share in a formal way their availability to produce. 
- Definition of new ICT tools to support the different phases of sales and order management processes: innovative tools have to be based on integrated provision of advanced services and interoperability with the existing legacies also through the adoption of existing standards for the documents exchanged along the network.

- Change in the knowledge management: the company needs to enlarge the knowledge base on customer requirements and formalize all the different features of the order with specific and dedicated services. This new knowledge base needs to be used during the design phase, in the shop and during production by different actors.

In the specific case of obese people as well as in other target groups like diabetics, elderly etc they have specific requirements for shopping clothes, which are related not only to their sizes, but which require taking a number of measures with the support of dedicated shop assistants or tailors and the production of specific items as well as the need of having fabrics, styles and patterns specific for them. These models and patterns are not always fully available in the shops, therefore the support of an on-line gallery that allows browsing on a number of dedicated items with 3D rendering and possibility of selecting variants would be very useful.

\section{$3 \quad$ Background}

In literature, there are many different approaches for the order management as well as for the partner search process. These approaches need to be adapated to the needs of customized products. For what concerns order management, while in [10] it is proposed an approach for the qualitative evaluation of the turbulence of the market in [11] it is explained how to increase degree of responsiveness with a new architecture based on Web Services and Ubiquitous Computing technologies for reliable real-time information. The TCFI sector, also analysed in [12,13], is populated by a number of small or micro enterprises, with limited resources for the adoption of innovative IT solutions, and requires the adoption of order management solutions based on exchange of documents based on SMTP or HTTP rather than on a fully SOA architecture for a step-by-step approach to integration of different modules.

The exchange of business documents along the supply chain for the production of textile and garments need to be formalized in the ModaML/TexSpin standard $[5,12,13]$ that has been included in the results of the eBIZ process [4]; till now the ordering, production and delivery of customized garments, however, is not fully covered by these standards and this work aims to contribute to improve them.

For what concerns the use of different criteria to select partners for supply networks they have been characterized in works developed by [14] and [2] who introduced the utilization of performance measures, usually known as KPIs, to better compare and select the suitable partners for every specific VO (that can be considered a particular type of supply network). These approaches emphasize the importance of selecting partners using a well-defined set of criteria, based on common attributes of each company. Taking into account the improvement of organizations that apply methodologies to measure their performance [16] as well as the improvement of collaborative networks that are 
establishing inter-organizational Performance Measurement Systems [15], the KPIs can be used as criteria to suggest supply network partners. This strategy has been used also by [7] and [8] who introduced other criteria besides KPIs, like trustworthiness and risk values. [18] also proposed the utilization of KPIs related to collaboration and commitment which are also revised and used in this paper. In literature there are many different KPIs to be used for different scope and applying different perspective to the partners evaluation according to the scope of the network to be created. No shared ontology for modeling KPIs, nor taxonomy of supplies and supply chain roles are available if not restricted to specific sector/application requirements. For the scope of this work, some important KPIs have been selected from literature and from real case studies and have been formalized in the Partner Profile.

\section{From Customized Order Creation to Collaborative Production}

In Figure 1, the processes from the order generation to the delivery of the customised items are depicted and the tools supporting the flow are highlighted with a light dotted grey circle. In particular the following processes are taken into consideration:

- sales process with product configuration

- network configuration process based on partner search

- $\quad$ order management based on standardized document format.

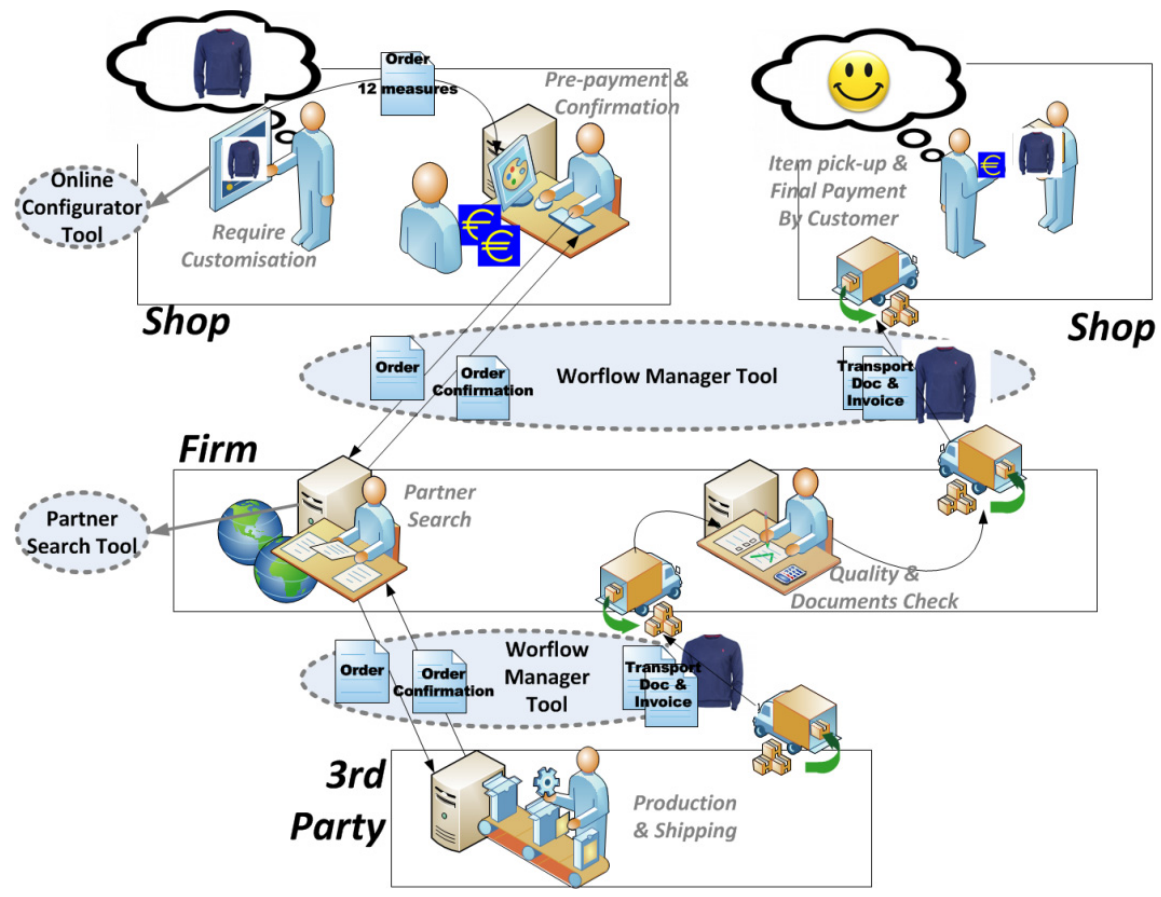

Fig. 1. Tool coverage on the knitted garment Pilot 


\subsection{The Sales Process: From Product Configuration to Order Dispatching}

The sales process is mainly supported by the introduction of an innovative Configuration user interface to be used by the shop assistant and consists of 3 main parts:

- A configurator used by the company to prepare an on-line collection and to define the customisable parameters made available to the target group of consumers

- A service to quickly get measures of obese people, which allows calculating a set of 12 body measures starting from 3 simple measures.

- An online order preparation and submission tool.

Using a rich graphical user interface, a consumer with the support of the shop assistant can browse a catalogue of items, select and configure them both aesthetically (for example by changing colour, accessories like buttons etc...) and functionally by entering his own measures and specific needs (like larger sizes, functional fabrics and adapted fashion options).

The order is created by a consumer with the support of a shop assistant using the online configurator and is complete of sensible data (related to the consumer and to the prepayment amount); then the order is automatically checked by the system (to avoid errors or incompleteness) and then dispatched to the producer that, with the support of other tools of the pilot, can identify the best suppliers.

\subsection{The Network Configuration Process: The Partner Search Tool}

The network configuration process runs when new $3^{\text {rd }}$ parties are needed for knitting or sewing the product requested by the customized order. The process is supported by a Partner Search tool which is based on available capability of each registered potential partner and on KPIs based on their past performance in case they have already collaborate [3]. The selection of partners is based on criteria related to the product features as from the received order but also on criteria to measure the performance of the partner in terms of quality, time, and price. With the Partner Search tool, it is possible to execute multi dimensional searches in order to retrieve partners that provide the best matches towards a set of identified KPIs. These KPIs can be chosen time by time according to the needs of the specific customized order to be produced giving different importance to capabilities, time, cost and quality.

In the specific case of the KGP one of the key criteria for the quick and successful selection of a supplier is the availability of (pre-configured) knitting machines. Therefore the tool can be used at operational level as a collaborative tool since it allows the suppliers to update their profiles with information on availability (in a given time frame) of their machines for the production of specific items. If necessary, the producer exchanges other information with the selected suppliers to plan and execute the production, until the item is physically delivered to consumer at the shop.

\subsection{The Order Management Process and Use of Data Exchange Standards}

The Workflow Manager (WfM) tool seamlessly supports the correct flow of information along a designed process that involves different actors. It applies rules checking the format and the content of the Business Documents and dispatches them 
to the correct receivers, also providing feedback on errors and anomalies, when necessary. This allows companies to save time when receiving many different orders for customised items, supporting them in dispatching the correct pieces of information to the correct partners.

The WfM architecture is actually based on an Enterprise Service Bus (ESB) that takes care of: managing the exchange of information with external applications/services (on-line configurator, ERP etc.), decoupling the specific way the information is transferred from an external application/service to the ESB and vice versa.

The flow of information generated by the creation of a customized order is usually more complex than the one generated by a standard order, given the amount of data and details to be managed after order collection till the delivery of the item to the final customer. This flow of information needs to be conveyed to the proper actors and tools in a way that is perfectly understandable and manageable by all of them in the shortest possible time. In the case of the TCFI sector, the most natural choice was to evaluate the adoption of the interoperability architecture proposed by $\mathrm{eBiz}^{\mathrm{TCF}}{ }^{2}$ [4] project, that encompasses the Moda- $\mathrm{ML}^{3}$ standard [5] for Textile and Clothing business documents. The eBIZ processes and documents fitting KGP have been identified and analysed, realizing that eBIZ does not provide a full coverage of the process underlying the creation and management of orders for customized garments. Therefore a set of eBIZ/Moda-ML documents that support the exchange of information for the on-demand production of customized knitted items has been conceived and will end up with the release of a proposal for an extension of the standard, submitted to the ongoing eBIZ CEN workshop ${ }^{4}$.

\section{Conclusions}

The KGP scenario presented in this paper describes innovative services to support SMEs in the application of advanced tools for enhanced sales process and collaborative production process. Beyond the benefits deriving by the adoption of a standard for the information exchange, it is important to remark the most innovative aspects emerged by the adoption of the proposed tools in the KGP scenario, are:

- Management of a "customised order" which is presently not supported by the standards in the TCFI sector: This work is a contribution to define a standard format for this kind of order for the Clothing sector, which can be applied to the ordering of different garments, not only knitted items.

- Creation of the order based on collaboration of different actors: the part of the order for "customisation" definition (aesthetical preferences and measures) is done in the on-line configurator and then completed with sensible data in the shop by means of

2 eBiz TCF is a project launched in January 2008 by the European Commission to boost ebusiness processes in the Textile/Clothing and Footwear (TCF) Industries website: http: / / ebiz-tcf.eu/

${ }^{3}$ Moda-ML is an initiative that aims to publicly offer tools and format specifications for the data exchange in networks of Textile/Clothing enterprises;website: http: / /www . moda-ml .org /

4 eBIZ workshop : http: //www. cen.eu/cen/News/PressReleases/Pages / PR-2012-01-23_eBiz.aspx 
the ERP company system. The management of the order is fully supported by tools integrated by the WfM.

- Possibility to model through business rules, defined and executed in the WfM properties on the structure and on the content of the documents that are not modelled by the standard.

- Definition and maintenance of information on possible production partners, not only derived from the administrative data but also from their past performances or provided directly, in a collaborative way, by the partners itself.

The integrated solutions that have been designed in order to optimize the automatic exchange of structured information, allow companies to reduces the overall time from the order generation to the production and delivery of a customized product as demonstrated in the KGP. The advantages of the proposed services are that each business partner involved in the process can express rules on the expected contents of the exchanged documents (i.e. presence of a pre-payment description in the order is necessary for its acceptance by the producer) and can specify actions to be triggered (i.e. the order is rejected and a rejection notification is sent to the shop). The advantages of the Partner Search tool are that each partner can collaboratively share its own available capability and the manufacturer can manage in a formal way all partner profiles according to reliable and updated performance measurement. This has demonstrated to increase quality of the partners selected both in terms of reliability and in terms of delivery time.

There are several potential extensions of the solution, among which to provide tool coverage also to support the manufacturer in the selection and publication of garments in the on-line configurator (for example, by providing a virtualisation of the items on obese morphotypes) and check applicability of the solutions to different kind of garments, in particular for those requiring more complex supply chains to be produced. Moreover the proposed solution has been conceived to be applicable to business environments beyond the ordering and production of knitted items and addressing different target groups (not only obese people). For example, the format of the standard documents is general enough to be applied to other kinds of clothes also requiring different sets of personalised measures and the partner profile can be applied as well to other kind of production.

Acknowledgement. This work has been partly funded by the European Commission through FP7 NMP CoreNet (Customer-ORiented and Eco-friendly NETworks for healthy fashionable goods) project (Grant Agreement No. 260169).

\section{References}

1. Zangiacomi, A., Fornasiero, R., Bastos, J., Azevedo, A., Franchini, V., Vinelli, A.: Reference Model Framework for Production of Small Series of Innovative and Fashionable Goods in Manufacturing Networks. In: Azevedo, A. (ed.) Advances in Sustainable and Competitive Manufacturing Systems. 23rd International Conference on Flexible Automation and Intelligent Manufacturing. Lecture Notes in Mechanical Engineering, pp. 1291-1303. Springer (2013)

2. Seifert, M., Eschenbächer, J.: Predictive Performance Measurement in Virtual Organization. In: Camarinha-Matos, L.M. (ed.) Emerging Solutions for Future Manufacturing Systems. IFIP, vol. 159, pp. 299-307. Springer, Boston (2005) 
3. Rotondi, D., Piccione, S., Sesana, M., Fornasiero, R.: Semantics and KPIs to improve partners selection for small series production. To be published on 18th International ICEConference on Engineering, Technology and Innovation, June 18-20, Munich Proceedings (2012)

4. eBiz TCF Reference Architecture available at http: / /ebiz-tcf.eu/reference-architecture/

5. ModaML 2011-1 version available at http: / /www . moda-ml . org/ moda-ml / imple $/$ moda $-m l-2011-1$. asp? 1 ingua $=e n \& p a g=0 \& m o d o=0$

6. Camarinha-Matos, L.M., Oliveira, A.I., Demsar, D., Sesana, M., Molina, A., Baldo, F., Jarimo, T.: VO Creation Assistance Services. In: Methods and Tools for Collaborative Networked Organizations, Springer, New York (2008)

7. Jarimo, T., Salkari, I., Bollhalter, S.: Partner Selection with Network Interdependencies: An Application. In: Camarinlia-Matos, L., Afsarmanesh, H., Ollus, M. (eds.) NetworkCentric Collaboration and Supporting Frameworks. IFIP, vol. 224, pp. 389-396. Springer, Boston (2006)

8. Crispim, J.A., Sousa, J.P.: Multiple Criteria Partner Selection in Virtual Enterprises. In: Camarinha-Matos, L.M., Afsarmanesh, H., Novais, P., Analide, C. (eds.) Establishing the Foundation of Collaborative Networks. IFIP AICT, vol. 243, pp. 197-206. Springer, Boston (2007)

9. Wiendahl, H.-H.: Fast and Reliable Order Management Design Using a Qualitative Approach. In: Olhager, J., Persson, F. (eds.) Advances in Production Management Systems. IFIP, vol. 246, pp. 237-244. Springer, Boston (2007)

10. Park, M., Shin, K., Jeong, H., Park, J.: A Framework for Enhancing Responsiveness in Sales Order Processing System Using Web Services and Ubiquitous Computing Technologies. In: Vallespir, B., Alix, T. (eds.) APMS 2009. IFIP AICT, vol.338, pp. 449-456. Springer, Heidelberg (2010)

11. Gessa, N., Cucchiara, G., De Sabbata, P., Brutti, A.: -A bottom-up approach to build a B2B sectorial standard: the case of Moda-ML/TexSpin. In: Panetto, H. (ed.) Interoperability of Enterprise Software Applications, Workshops of the INTEROP- ESA International Conference, Geneve, February 22, pp. 249-260. Hermes Science Publishing, Paris (2005) ISBN-1-905209-45-5

12. De Sabbata, P., Gessa, N., Brutti, A., Novelli, C., Frascella, A., D’Agosta, G.: Standard creation and adoption for SME networks. In: Panetto, H. (ed.) Interoperability for Enterprise Software and Applications. Proceedings of the Workshops and the Doctorial Symposium of the I-ESA International Conference 2010 (Workshop: Standards - a Foundation for Interoperability), Coventry, April 13, pp. 41-51. Nacer Boudjlida, ISTE/Wiley (June 2010) ISBN 978-1-84821-270-1

13. Grudzewski, W.M., Sankowska, A., Wantuchowicz, M.: Virtual Scorecard as a Decisionmaking Tool in Creating Virtual Organisation. In: Camarinha-Matos, L.M., Afsarmanesh, H., Ortiz, A. (eds.) Collaborative Networks and Their Breeding Environments. IFIP, vol. 186, pp. 293-300. Springer, Boston (2005)

14. Gunasekaran, A., Williams, H.J., Mcgaughey, R.E.: Performance measurement and costing system in new enterprise. Technovation 25(5), 523-533 (2005)

15. Lambert, D.M., Pohlen, T.L.: Supply Chain Metrics. International Journal of Logistics Management 12(1), 1-19 (2001) 